\title{
Mapping the expansion of galamsey gold mines in the cocoa growing area of Ghana using optical Remote Sensing
}

\author{
B. Snapir ${ }^{\mathrm{a}}$, D.M. Simms ${ }^{\mathrm{a}}$, T.W. Waine $\mathrm{e}^{\mathrm{a}, *}$ \\ ${ }^{a}$ Cranfield University, Cranfield, Bedfordshire, MK43 OAL, UK
}

\begin{abstract}
Artisanal gold mining (galamsey) and cocoa farming are essential sources of income for local populations in Ghana. Unfortunately the former poses serious threats to the environment and human health, and conflicts with cocoa farming and other livelihoods. Timely and spatially referenced information on the extent of galamsey is needed to understand and limit the negative impacts of mining. To address this, we use multi-date UK-DMC2 satellite images to map the extent and expansion of galamsey from 2011 to 2015. We map the total area of galamsey in 2013 over the cocoa growing area, using $k$-means clustering on a cloud-free 2013 image with strong spectral contrast between galamsey and the surrounding vegetation. We also process a pair of hazy images from 2011 and 2015 with Multivariate Alteration Detection to map the 2011-2015 galamsey expansion in a subset, labelled the change area. We use a set of visually interpreted random sample points to compute bias-corrected area estimates. We also delineate an indicative impact zone of pollution proportional to the density of galamsey, assuming a maximum radius of $10 \mathrm{~km}$. In the cocoa growing area of Ghana, the estimated total area of galamsey in 2013 is 27,839 ha with an impact zone of 551,496 ha. In the change area, galamsey has more than tripled between 2011 and 2015, resulting in 603 ha of direct encroachment into protected forest reserves. Assuming the same growth rate for the rest of the cocoa growing area, the total area of galamsey in 2015 is estimated at 43,879 ha. Galamsey is developing along most of the river network (Offin, Ankobra, Birim, Anum, Tano), with downstream pollution affecting both land and water.
\end{abstract}

Keywords: gold mining, galamsey, cocoa, pollution, UK-DMC2, change detection

\footnotetext{
* Corresponding author, t.w.waine@cranfield.ac.uk
} 


\section{Introduction}

Gold mining in Ghana (Africa) is a complex system broadly divided into two groups, (i) large-scale mining concessions (modern surface / underground mining) and (ii) small-scale mines (artisanal surface mining) also called galamsey. The former contributes significantly to the overall economy of the country through fiscal revenue (Fonseca, 2004). However, they have little interaction with the local economies, they often lead to forced relocation of communities and are an undeniable source of environmental pollution (Aragon \& Rud, 2013). In comparison, even though it is mostly illegal (Teschner, 2012), galamsey brings direct income to the miners and their families, and stimulates local trade related to mining (Amankwah, 2013). Unfortunately, as it is mainly surface mining, it results in significant destruction of natural vegetation and farm land, removal of soil, and diversion of water bodies. The mining process also leads to dust pollution, water pollution from increase in sediments (Kusimi et al., 2014) and the introduction of mercury which also contaminates soil (Serfor-Armah et al., 2004). In 2011 the Ghana Water Company Limited was forced to temporarily stop treating water because the Birim river was too polluted to be treated for domestic use (Amankwah, 2013).

Gold and cocoa are the backbone of Ghana's exports, recording respectively US $\$ 4,388.06$ million and US $\$ 2,612.87$ million which together account for $53.0 \%$ of total export receipts in 2014 (ISSER, 2015). Unfortunately the two activities struggle to coexist (Boateng et al. 2014). First, gold and cocoa are competing for land and labour - cocoa land is converted to mining and/or farmers abandon cocoa for trying their chance in neighbouring galamsey. Gold mining is favoured as it can provide quick profit compared to the poorly-paid seasonal cocoa activity. Second, the pollution from galamsey is reported to affect cocoa yield - farmers observe early fall of immature pods, wilting, and yellowing of leaves in plantations close to mined area (Boateng et al., 2014). Nonetheless, galamsey is also reported to have positive impacts on the cocoa activity. Rather than abandoning their farm, some farmers earn money from gold mining during the off-farming season and reinvest it in farming through hiring of labour and purchasing of agrochemicals otherwise unaffordable (Hilson \& Garforth, 2013. Okoh \& Hilson, 2011).

So far, most of the research on the galamsey problem in Ghana has relied on local evidence of the negative impacts of mining such as interviews of farmers (Boateng et al., 2014), unsafe concentration of mercury in samples of water / soil (Serfor-Armah et al., 2004, Armah et al., 2010) and in human blood/urine (Adimado \& Baah 2002), and occurrence of diseases (Opare et al., 2012). Remote Sensing has been used to explore land use and land cover changes related to gold mining in local mining areas (Basommi \& Guan, 2015, Basommi et al. 2015, Manu et al., 2004 Kusimi, 2008). These studies looked at broad class changes (Open Savannah, Closed Savannah, Bare areas, Settlements, Water bodies) after individual classification (using ISODATA or Maximum Likelihood) of multi-date Landsat images. Overall, the mining activity was associated with conversion of savannah areas into bare ground and settlement over periods of 
about 10 years, but none of these studies has delineated the mining areas. In regions of the Brazilian Amazon forest, artisanal gold mining has been mapped using cloud-free Landsat images. Almeida-Filho \& Shimabukuro (2002) used a postclassification change detection approach based on image segmentation and k-means clustering, and Asner et al. (2013) used the Carnegie Landsat Analysis System-lite (CLASlite). Almeida-Filho \& Shimabukuro (2000) also showed that mining areas could be identified from Synthetic Aperture Radar (SAR) images from JERS-1. In comparison, there are currently no reliable data on the location and the extent of galamsey in Ghana (Aragon \& Rud, 2013). A timely and comprehensive map of galamsey is necessary to measure the extent of the problem, and to design efficient ground measurement campaigns to appraise the magnitude and effects of the pollution. Monitoring the evolution of galamsey is also valuable for the inter-ministerial task force against illegal mining (created in May 2013 by the President of Ghana, John Dramani Mahama) to better target their intervention (arrest of illegal miners, seizing of mining equipment).

In this paper, we use multi-date optical images acquired by UK-DMC2 to (i) map the extent and evolution of galamsey in southern Ghana from 2011 to 2015, and (ii) provide a preliminary assessment of the potential extent of pollution. UK-DMC2 is a British multi-spectral imaging satellite part of the Disaster Monitoring Constellation, operating in green, red and near infrared at $22 \mathrm{~m}$ resolution (table 1).

\section{Methodology}

\subsection{Data and study area}

The study area (Fig. 1) was selected to cover the cocoa growing area of southern Ghana where most of the galamsey is concentrated. While northern Ghana is hot and dry, the cocoa growing area is hot and wet, prone to cloud cover and haze, particularly during the rainy season from April to mid-November. The MODIS cloud fraction product (Platnick et al. 2003) shows the study area had an average cloud fraction of 0.83 in 2015, with a minimum of 0.53 in December. A search of archive imagery between 2011-2015 from the Landsat mission only returned one cloud-free but hazy Landsat-8 images from 11 January 2015. Thick cloud cover and/or groups of scattered clouds made the other Landsat images unusable, even for multi-temporal compositing. Alternatively, a search of archive imagery from UK-DMC2 for the same period found three usable images of varying quality - 19 January 2011, 1 January 2013, 13 January 2015. The image from 2013 was cloud free and was used to map the total area of galamsey within the study area. The 2011 and 2015 images, used to map the 2011-2015 galamsey expansion, had a limited extent compared to the 2013 image and $29 \%$ of the overlap image (mainly in the southeast of the overlap), affected by thick haze, was removed during the change detection analysis. Consequently, the mapping of the galamsey expansion only covers $38 \%$ of the study area, referred as the change area (Fig. 1).

In the DMC imagery, galamsey appears as ribbons of highly reflective land, along river channels, with strong spectral contrast to the surrounding vegetation 


\begin{tabular}{cc} 
Table 1: Technical characteristics of UK-DMC2 L1T product \\
\hline Resolution & $22 \mathrm{~m}$ \\
Swath & $660 \mathrm{~km}$ \\
& Green $(0.52-0.62 \mu \mathrm{m})$ \\
Spectral bands & Red $(0.63-0.69 \mu \mathrm{m})$ \\
& NIR $(0.76-0.9 \mu \mathrm{m})$ \\
Bit depth & $8 \mathrm{bit}$ \\
Geometric RMS error & $11-16.5 \mathrm{~m}$ \\
Signal to Noise Ratio & $100: 1$ \\
\hline
\end{tabular}

(Fig. 3). Spectrally separating galamsey from areas of settlements is difficult as both contain bare soil, and the pixel size is too coarse to utilise the image texture.

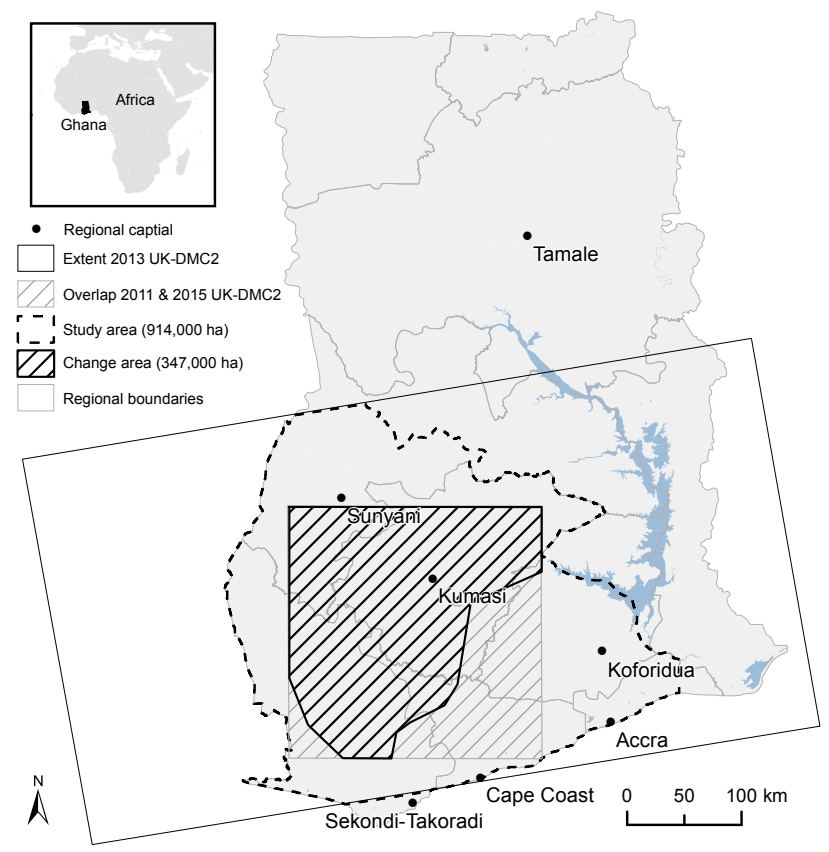

Figure 1: Study area in southern Ghana with extent of the 2013 UK-DMC2 image and overlap area of the UK-DMC2 images from 2011 and 2015. The map of galamsey in 2013 covers the whole study area. Because of haze, the map of galamsey expansion only covers $38 \%$ of the study area, labelled change area.

\subsection{Total area of galamsey in 2013}

The total area of galamsey was mapped using unsupervised classification of the UK-DMC2 L1T image acquired 1 January 2013 and visual interpretation of Google Earth ${ }^{\circledR}$ imagery (Fig. 2(a)). We did not use supervised classification 


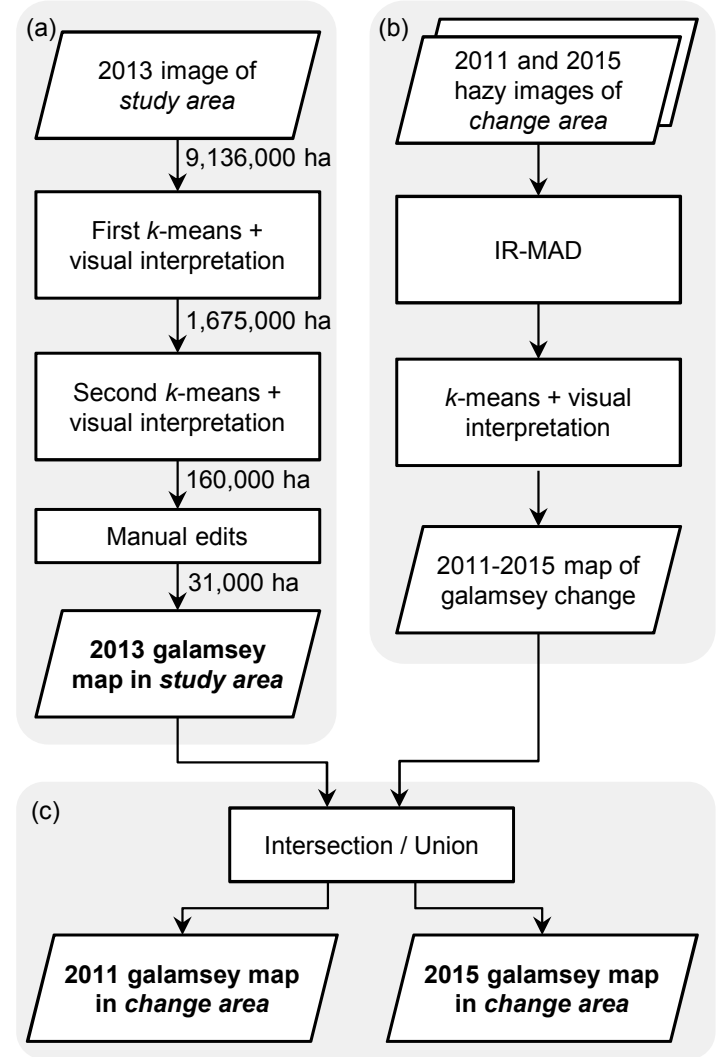

Figure 2: Overall methodology to generate (a) the 2013 galamsey map covering the whole study area from the 2013 cloud-free UK-DMC2 image (the area values show the progressive isolation of the galamsey area), (b) the map of 2011-2015 galamsey expansion covering only the change area from the 2011 and 2015 hazy UK-DMC2 images, and (c) the maps of galamsey in 2011 and 2015, also limited to the change area.

as galamsey is a relatively low proportion of the study area, thus visual interpretation of a large number of non-galamsey pixels would have been required to collect a representative sample (Plourde \& Congalton, 2003).

The image was first subset to the study area and the original Green, Red, and Near Infra-Red bands were converted to top of atmosphere reflectance according to the method in Crowley \& Mackin (2008). A Normalized Difference Vegetation Index (NDVI) band was added as a new image layer to the reflectance bands to improve the spectral differences between vegetated and non-vegetated surfaces. We progressively separated galamsey from other land covers through two successive unsupervised classifications, each using $k$-means clustering with 50 classes. At each iteration, the classes were labelled by visual interpretation of the original false-colour image, and the non-galamsey classes were removed from the analysis. The number of classes is a trade-off between having enough 
classes to discriminate galamsey, while maintaining manual interpretation of these classes manageable. Finally the area classified as galamsey was manually edited by visual interpretation of Google Earth ${ }^{\circledR}$ imagery, removing another 129,000 ha of non-galamsey areas (urban areas, roads, bare ground).

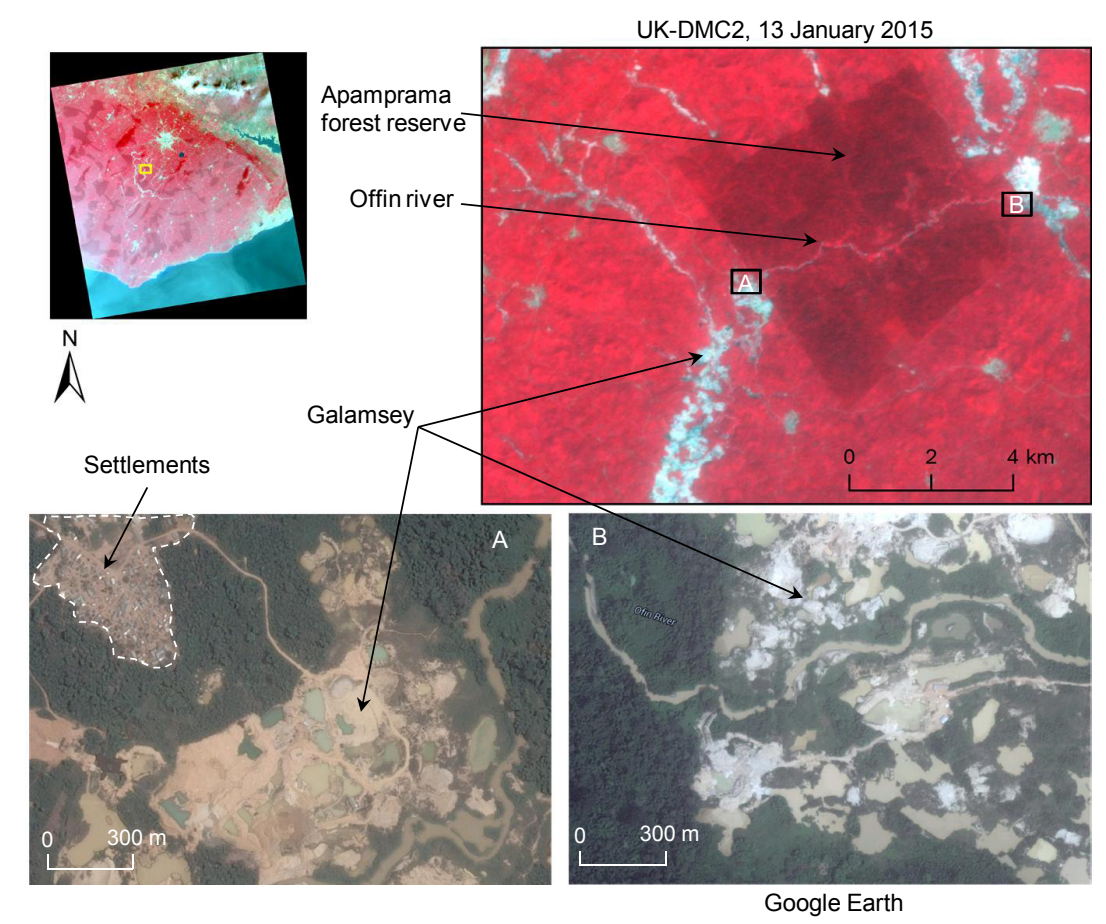

Figure 3: Example of galamsey and settlements as seen on the 2015 UK-DMC2 near-infrared false colour image (top right) and on Google Earth imagery (bottom). Google Earth imagery, (C)2016 Google, Image (C)2016 CNES / Astrium, Image (C)2016 DigitalGlobe.

\subsection{Galamsey change between 2011 and 2015}

Previous remote sensing studies on Ghanaian galamsey have investigated broad changes between two/three individually-classified images (Basommi \& Guan, 2015, Basommi et al., 2015, Kusimi, 2008, Manu et al., 2004). Postclassification comparison applied to the hazy 2011 and 2015 images led to obvious classification errors that would propagate to the change detection analysis. Attempts at haze reduction based on dark pixel subtraction (Makarau et al. 2014) introduced considerable noise into the image data and were considered unsuitable. Instead, we used iteratively re-weighted Multivariate Alteration Detection (IR-MAD) (Fig. 2(b)), a state-of-the-art unsupervised change-detection methodology to maximise differences relating to land-cover change as opposed to changes in illumination and atmospheric conditions (Canty \& Nielsen, 2008). The IR-MAD also allows specifying a change threshold well-suited to isolate the relatively strong change in reflectivity from vegetation to galamsey. 
The IR-MAD transform uses Canonical Correlation Analysis to find the vector coefficients $a$ and $b$ that maximise the variance of the scalar difference image $D=a^{T} F-b^{T} G$, where $F$ and $G$ are two $N$-dimensional images acquired at different times (Canty \& Nielsen, 2006; Nielsen et al., 1998). This results in new images $U=a^{T} F$ and $V=b^{T} G$ where the first band of $U$ is maximally correlated with the first band of $V$. Band two of $U$ and $V$ are orthogonal to the first band and so on. The uncorrelated MAD variates are generated from the paired differences of the transformed images band-by-band, $M_{i}=$ $U_{N-i+1}-V_{N-i+1}, i=1 \ldots N$. The MAD variates provide a convenient way to threshold the change pixels as the no-change pixels are normally distributed about the mean. The probability of change is determined from the chi-square distribution function $P_{\chi^{2}, N}(z)$ for each sample of $z$ from the sum of the squares of the standardised MAD variates:

$$
Z=\sum_{i-1}^{N}\left(\frac{M_{i}}{\sigma_{M_{i}}}\right)^{2}
$$

where $\sigma_{M_{i}}$ is the variance of $M_{i}$. The sensitivity of the MAD variates to change is improved by iteratively re-weighting observations using the probability of no-change until the change in the canonical correlations falls below a threshold.

Using code available from Canty (2015), MAD variates were generated for the overlap area of the 2011 and 2015 imagery. Visual inspection of a false colour composite of the three MAD variates (Fig. (4) shows in the first variate (red), areas of change along the river network and urban areas where forest and agricultural land have been cleared. Reflectance changes in existing areas of galamsey are visible in the second variate (green). The spectral differences associated with land-use change between images are maximised and categories of change are sorted into uncorrelated image components (Canty \& Nielsen, 2006). Change-pixels can be extracted without the need for any pre-classification that may introduce labelling error into the change detection. The effect of thin haze is also greatly reduced as it represents a smaller variation in pixel values between dates than land-use change.

Changes in the agricultural and forest areas relating to harvest patterns or differences in phenology are not visible as the land cover is relatively homogeneous at the resolution of the DMC, with each pixel representing a mix of tree crops or the natural forest canopy. The MAD approach effectively filters out pseudo-changes within the agricultural area and the blocks of natural forest (low change-probabilities) because they are correlated between images.

The change pixels were extracted using a threshold of no-change probability $>0.95$ as suggested in Canty \& Nielsen (2008). Noisy change pixels caused by thick haze (mainly in the southeast of the overlap area) were manually removed, and the analysis continued only for the pixels within the change area.

The remaining change pixels were then clustered into 50 spectral classes using $k$-means and labelled manually by visual interpretation of the images. Classes corresponding to areas of change not associated with mining activity 

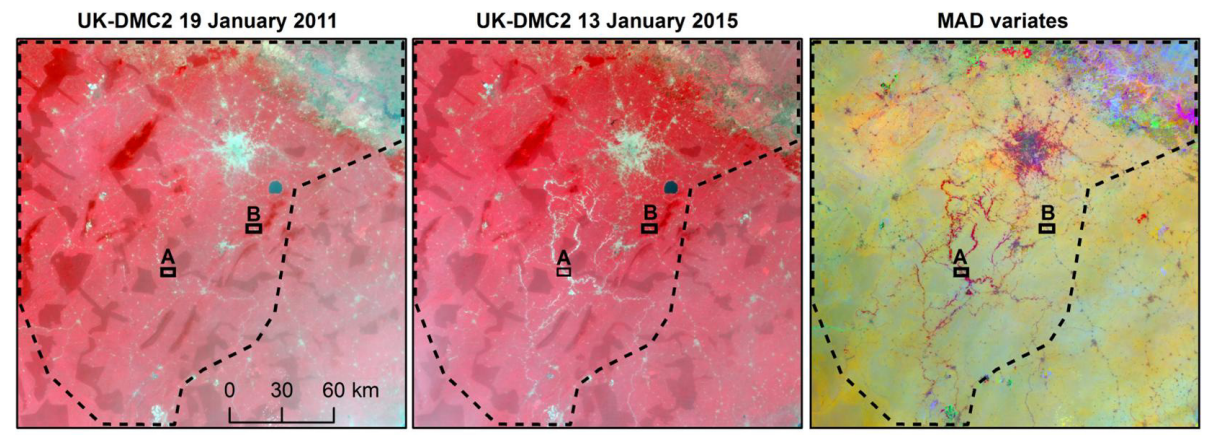

Old galamsey
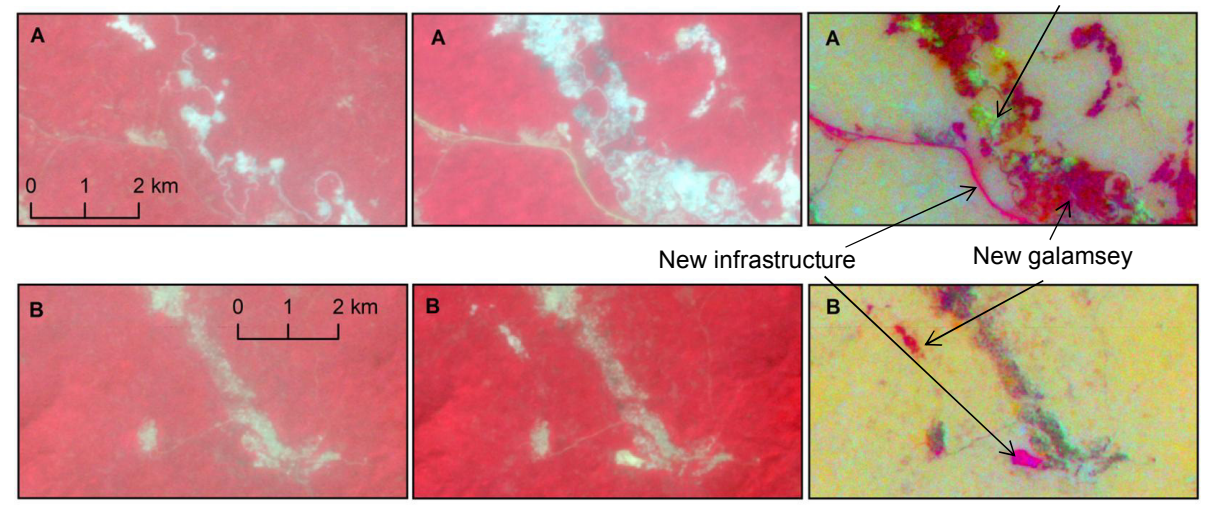

Figure 4: UK-DMC2 near-infrared false colour image subsets from 19 January 2011 (left), 13 January 2015 (centre) and the three MAD variates (right) (red $=$ variate 1 , green $=$ variate 2 , blue $=$ variate 3 ). The first MAD variate (in red) shows areas along the river where forest and agricultural land have been cleared and areas of older galamsey appear in variate 2 (green). The dashed contour shows the change area (with only light haze) for which the change pixels were then classified to isolate the galamsey.

were removed. The resulting mask was used to subset the change pixels from the MAD image.

\subsection{Maps of galamsey in 2011 and 2015}

While cloud/haze prevented a direct detection of the area of galamsey in 2011 and in 2015, we derived maps of area of galamsey for these years by combining (union/intersection) the 2011-2015 galamsey expansion with the map of total galamsey area in 2013 (Fig. 2(c)). This combination is limited to the coverage of the 2011-2015 galamsey expansion, i.e. limited to the change area. These maps enabled estimates of the area of galamsey in 2011 and in 2015.

\subsection{Extent of pollution}

Several studies based on the analysis of soil/water samples have proved that the pollution from galamsey is real, but the extent and intensity of the pollution is not known. Aragon \& Rud (2013) arbitrarily used a $20 \mathrm{~km}$ impact 
zone around large-scale mining concessions. Lobo et al. (2015) measured water siltation caused by artisanal gold mining in the Tapajs River Basin in Brazil by relating Landsat surface reflectance with in situ measurements of water reflectance and total suspended solids. In the absence of in situ data explaining how the galamsey pollution propagates in the environment, we computed an arbitrary impact zone with radius $r$ proportional to the proportion of galamsey $p$ and a maximum value $r_{\max }$ of $10 \mathrm{~km}$, i.e. $r=p \cdot r_{\max }$. For each galamsey pixel, the proportion of galamsey was computed as the ratio between the number of galamsey pixels and the total number of pixels within a $10-\mathrm{km}$-radius window. This impact zone is only indicative as for example, in the case of water siltation, results from Lobo et al. (2015) show a downstream effect which extends beyond $10 \mathrm{~km}$.

\section{Accuracy assessment}

The use of IR-MAD for detecting the 2011-2015 galamsey expansion removes the potential error from a postclassification comparison approach (Foody, 2002). However errors remain because of forest loss not associated with galamsey and boundary conditions between landcover types related to the resolution of the imagery, so called mixed pixels. The map of total area of galamsey in 2013, although manually edited, is subject to the same sources of error as it is based on the original image pixels. Error caused by misregistration between images was assumed to be minimal as UK-DMC2 L1T images are orthorectified with sub-pixel RMSE.

To assess the accuracy within the whole mapped area of galamsey a pure random sample of $0.2 \%$ (2152 pixels) was selected and visually interpreted using Google Earth (Fig. 3). Sample interpretations were cross-checked with the original false-colour imagery to reduce any mislabelling errors caused by the difference in timing between the DMC and the Google Earth image base. The sample points were then grouped into galamsey, settlements including roads, clear-cut forest and other. A small number of points (31) were excluded because of uncertain interpretation or missing/cloudy imagery on Google Earth.

Table 2 shows a similar accuracy (0.80 to 0.93$)$ across the maps. The lower accuracy for the 2015 galamsey map in the change area $(0.80)$ is caused by the misclassification of clear-cut forest areas. Errors also come from settlements close to galamsey that are likely to be directly related to the growth in mining, as also suggested by Basommi \& Guan (2015), Basommi et al. (2015), Manu et al. (2004), and Kusimi (2008).

The proportion of correctly labelled pixels, although high $(>80 \%)$, shows how areas calculated from counting labelled pixels can lead to bias in area figures (Gallego, 2004). The total area estimates from the galamsey maps were bias corrected using the proportion correct as a correction factor.

A limitation of the accuracy assessment is that only commission errors are considered within the galamsey areas. Although a visual inspection revealed no obvious omissions, no quantitative analysis was conducted so the figures presented are considered to be lower-bound estimates of the galamsey areas. 
Table 2: Cross tabulation (counts) of the mapped galamsey and image-interpreted sample points for the 2011, 2013, and 2015 galamsey map in the change area, and the 2013 galamsey map in the study area. Accuracy measured as the proportion of correct galamsey pixels (p. correct) from the total minus the excluded points (total). A total of 2152 points were used (galamsey (galam.) 1682, settlements (settl.) 332, clear-cut (c-cut) 64, other 43 and excluded (ex.) 31). The sample proportion is equal across all the maps (0.2\%). Some sample points are common to multiple years (e.g. the 497 points for 2011 are part of the 1011 points for 2013).

\begin{tabular}{ccrrrrrrr}
\hline Extent & Year & Galam. & Settl. & C-cut & Ex. & Other & Total & P.correct \\
\hline Change & 2011 & 438 & 16 & 32 & 3 & 11 & 497 & 0.88 \\
area & 2013 & 944 & 19 & 35 & 6 & 13 & 1011 & 0.93 \\
Study & 2015 & 1490 & 51 & 312 & 24 & 21 & 1874 & 0.80 \\
\begin{tabular}{c} 
area \\
\hline
\end{tabular} & & 1136 & 32 & 55 & 13 & 35 & 1258 & 0.90 \\
\hline
\end{tabular}

This is in line with the objectives of the paper and shows that even a conservative approach captures a significant expansion in galamsey.

\section{Results}

\subsection{Total area of galamsey in 2013}

The estimated total area of galamsey in January 2013 (cloud-free image) is 27,839 ha (bias corrected), and the corresponding impact zone covers an area of 551,496 ha. Fig. 5 shows that the overall layout of galamsey is matching the network of rivers. Practically, surface mining can only occur over unconsolidated rocks, thus miners prospect gold deposits mainly in river bed alluvium and colluvium (Hilson, 2002). Clear water is also necessary in the gold extraction process which in return leads to contamination of the rivers with excess sediment and mercury used for the amalgamation.

\subsection{Galamsey expansion 2011-2015}

Table 3 summarises the bias-corrected area estimates for 2011, 2013, and 2015 within the change area. The rate of expansion has increased from $+12,376$ ha $(+113 \%)$ for $2011-2013$ to $+13,414$ ha $(+58 \%)$ for $2013-2015$. So the galamsey area has more than tripled from 10,907 ha in 2011 to 36,696 ha in 2015. Assuming that the rest of the galamsey in the study area have expanded at the same rate than the galamsey in the change area, we extrapolated total area estimates for 2011 (13,042 ha) and 2015 (43,879 ha), based on the available figure for 2013.

Fig. 6] shows where galamsey has propagated. Overall, since 2011 galamsey has intensified in the Ashanti district, upstream of the Offin river, potentially worsening the environmental impact due to downstream pollution. After 2013, gold prospecting has also spread in new narrow ribbons along tributaries of the main rivers.

\subsection{Encroachment into protected forest reserves}

Several protected forest reserves, in vicinity of a river, are directly encroached on by galamsey. The Anhwiaso East, the Tano Ofin Extension, the Upper 


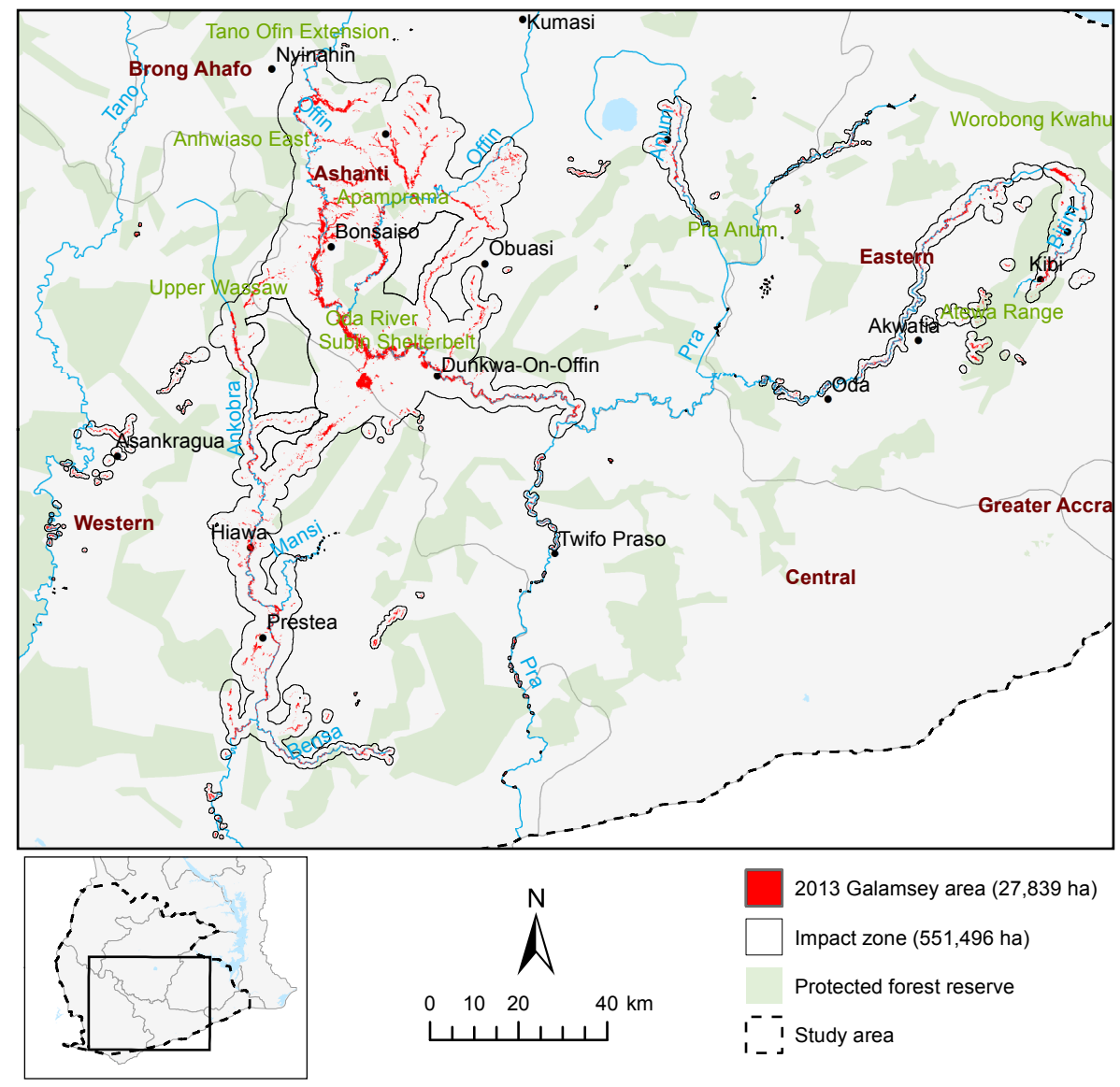

Figure 5: Total area of galamsey in 2013 in the study area, with impact zone proportional to the density of galamsey and assuming a maximum radius of $10 \mathrm{~km}$

Table 3: Bias-corrected estimates of galamsey area in 2011, 2013, and 2015, for the change area and the whole study area. The 2011 and 2015 estimates for the study area are extrapolated by applying the expansion rate found for the change area. For 2013, the biais correction for the change area (0.93) and for the study area $(0.90)$ are different because the study area contains additional sample points compared to the change area.

\begin{tabular}{lccl}
\hline \multicolumn{5}{c}{ Change area } \\
Year & Pixel count (ha) & Bias correction & Estimate (ha) \\
\hline 2011 & 12,376 & 0.88 & 10,907 \\
2013 & 24,936 & 0.93 & $23,282(+12,377)$ \\
2015 & 46,211 & 0.80 & $36,696(+13,414)$ \\
\hline \multicolumn{4}{c}{ Study area } \\
Year & Pixel count (ha) & Bias correction & Estimate (ha) \\
\hline 2011 & \multirow{3}{*}{0.90} & $13,042^{*}$ \\
2013 & 30,799 & & $27,839(+14,797)$ \\
2015 & & & $43,879^{*}(+16,040)$ \\
\hline *Extrapolated
\end{tabular}




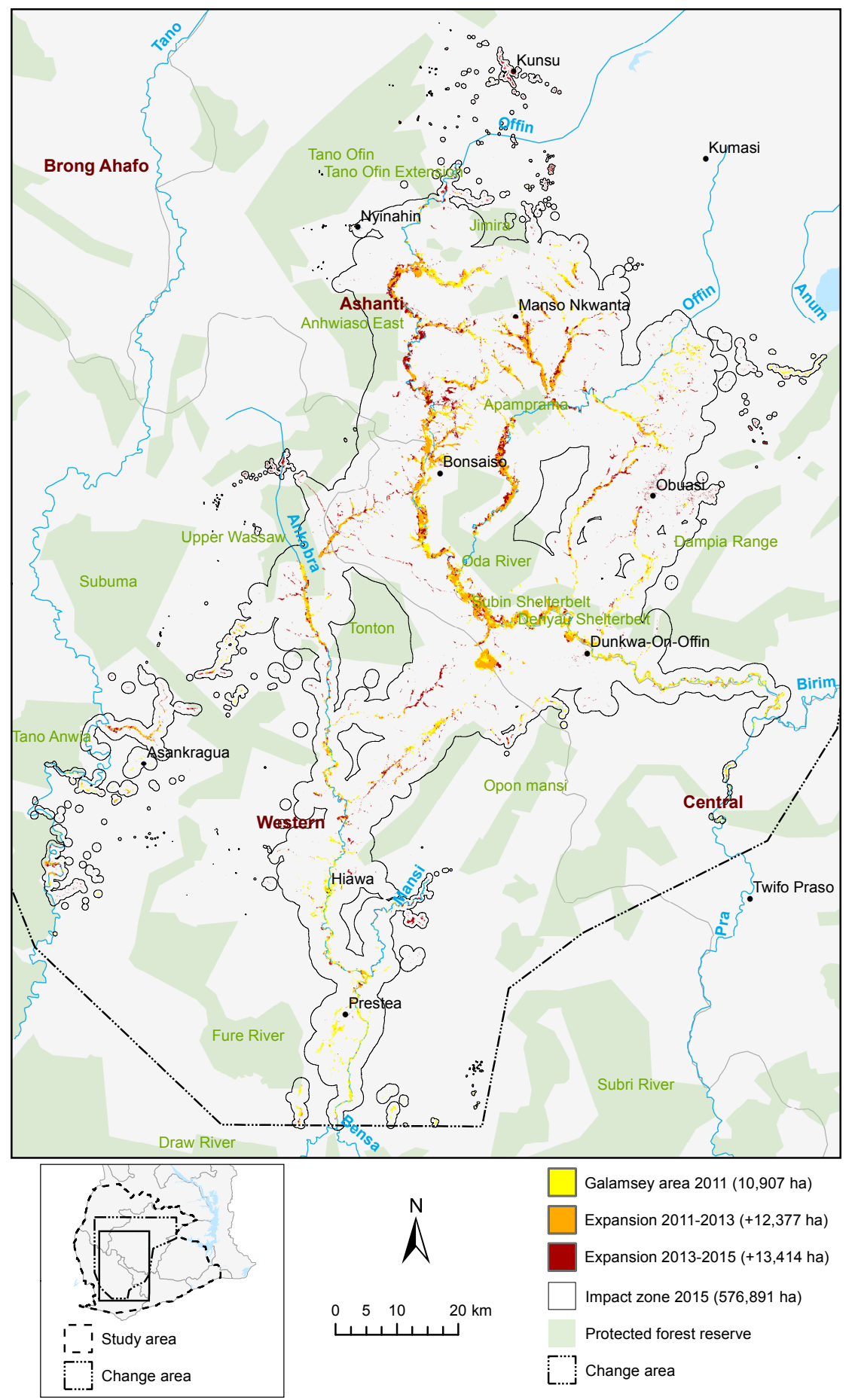

Figure 6: Expansion of galamsey in 2011, 2013, and 2015 in the change area. The impact zone is for the area of galamsey in 2015 
Table 4: Encroachment of galamsey into protected forest reserves within the change area

\begin{tabular}{lcc}
\hline Year & Forest encroachment (ha) & Area in impact zone (ha) \\
\hline 2011 & 53 & 53,645 \\
2013 & $144\left(332^{*}\right)$ & $40,772\left(50,842^{*}\right)$ \\
2015 & 603 & 65,625 \\
\hline
\end{tabular}

*Figures for the study area

Wassaw, the Oda River, the Subin Shelterbelt, the Denyau Shelterbel, the Tano Nimiri, the Pra Anum, and the Atewa Range are among the most affected reserves. Sometimes the ribbon of galamsey appears to stop at the edge of the reserves such as the Apamprama forest (Fig 3). The pollution however, must affect the ecosystem of the reserve, especially when polluted water runs across.

Table 4 shows that reserve encroachment has significantly increased from 53 ha to 603 ha between 2011 and 2015 within the change area. In terms of pollution, 65,625 ha of forest reserve are within the 2015 impact zone.

\section{Discussion}

\subsection{Impact on cocoa}

The direct encroachment of galamsey on cocoa plantations could not be assessed because of lack of ancillary information on their location and because they could not be identified on the UK-DMC2 imagery. However, out of the six cocoa-growing districts (Ashanti, Brong Ahafo, Eastern, Central, Western, Volta), four districts are affected by galamsey. In addition to the direct destruction of cocoa trees with insufficient to no financial compensation, cocoa is also affected by the polluted water used for irrigation, and the lack of labour who favour mining over working in the cocoa plantations (Boateng et al., 2014).

While galamsey was identified as a potential cause of a lower-than-expected cocoa production in Ghana in 2014/2015, the true causes remain unknown (Ecobank Group, 2015). Late delivery of fertilisers, adverse weather conditions, ageing of cocoa trees, black pod disease, smuggling of cocoa beans in Ivory Coast due to depreciation of the Ghanaian currency are other potential causes.

As mentioned in the introduction, galamsey is also reported to provide some farmers with additional income to take better care of their cocoa farms. This positive economical feedback comes at a high price as the depleted mined areas result in abandoned polluted land unsuitable for any livelihoods.

\subsection{Monitoring galamsey}

Using Remote Sensing, we identified the galamsey area and assessed its expansion between 2011 and 2015. Change detection techniques applied to future images could help avoiding further out-of-control proliferation. As the high occurrence of clouds/haze on optical imagery strongly limits change detection analysis, SAR imagery, now freely available from Sentinel-1, could be used to monitor galamsey using change in backscatter between two images AlmeidaFilho \& Shimabukuro, 2000). Higher-resolution commercial SAR imagery (e.g. 
Radarsat-2, CosmoSkymed, ALOS-2) may be needed to detect the smaller strips of galamsey.

Our galamsey maps do not differentiate between active and abandoned galamsey. The lifetime of a galamsey will vary according to the amount of gold, the number of miners and their equipments, and the intervention of the anti-galamsey task force. Active galamsey could be mapped using the interferometric coherence between two multi-temporal Sentinel-1 images (Milisavljevic et al. 2010). Low coherence would correspond to active galamsey where the bare soil surface has been disrupted between the two SAR images, and high coherence would correspond to the abandoned open pits.

\subsection{Galamsey pollution}

From our map of galamsey area, it is now possible to design an efficient ground measurement campaign with, for example, soil and water samples taken at intervals along transects perpendicular to the ribbon of galamsey. Such measurements would inform on the intensity of the pollution with regard to the density of galamsey, and how the pollution may decrease with the distance to the galamsey.

Regarding the impact of galamsey on cocoa, a map of the cocoa area would be a prerequisite to assess the conversion of cocoa to mining and areas potentially affected by galamsey pollution.

\section{Conclusion}

Using multi-temporal UK-DMC2 imagery along with unsupervised classifications and MAD, we generated (1) a map of the galamsey area in 2013 for the cocoa-growing area in southern Ghana (study area), and (2) a map of the expansion in galamsey area between 2011, 2013, and 2015, limited to the central part $(38 \%)$ of the study area (change area). Visual interpretation of 2152 random sample points suggested that at least $80 \%$ of the detected pixels are actual galamsey, the main confusion being with settlements.

For 2013, the estimated total area of galamsey after bias correction is 27,839 ha. Assuming that the extent of the galamsey pollution is proportional to the density of galamsey with a maximum impact radius of $10 \mathrm{~km}$, the impact zone covered 551,496 ha. In terms of expansion, only in the change area, galamsey has more than tripled between 2011 and 2015. Applying the same rate of expansion to the rest of the study area led to a total galamsey area estimated at 43,879 ha in 2015 .

Destruction of vegetation and pollution of soil and water make galamsey a serious threat to the environment and human health. Between 2011 and 2013, galamsey has dominantly expanded upstream of the Offin river in the Ashanti region, potentially amplifying its environmental impact due to downstream effect. From 2013 to 2015, galamsey has further spread to small tributaries of the main rivers. Our maps also show that galamsey is encroaching on protected forest reserves - 603 ha of encroached forest in 2015 within the change area. A 
map of agricultural fields would be needed to assess the encroachment on agriculture, especially on cocoa plantations which represent a key source of revenue in Ghana.

Galamsey is a complex socio-economical activity which struggles to coexist with other livelihoods. Mining has positive impacts on the local populations through the income it generates and through its associated trades. It also provides some farmers with the required money to take care of their cocoa plantations. These positive impacts must be balanced with the undeniable destruction and pollution of agricultural lands. Therefore mining should only continue by means which minimise its environmental impact. Change detection applied to future imagery can be used to reliably monitor the development of galamsey and help understand its pollution aspect, which is essential for better-informed actions.

\section{Acknowledgments}

The authors would like to thank Armajaro Research Limited for sponsoring this research.

\section{References}

Adimado, A. A., \& Baah, D. A. (2002). Mercury in Human Blood, Urine, Hair, Nail, and Fish from the Ankobra and Tano River Basins in Southwestern Ghana. Bulletin of Environmental Contamination and Toxicology, 68, 339346. doi:10.1007/s001280259.

Almeida-Filho, R., \& Shimabukuro, Y. E. (2000). Detecting areas disturbed by gold mining activities through JERS-1 SAR images, Roraima State, Brazilian Amazon. International Journal of Remote Sensing, 21, 3357-3362. URL: http://www.tandfonline.com/doi/abs/10.1080/ 014311600750019967 . doi:10.1080/014311600750019967.

Almeida-Filho, R., \& Shimabukuro, Y. E. (2002). Digital processing of a Landsat-TM time series for mapping and monitoring degraded areas caused by independent gold miners, Roraima State, Brazilian Amazon. Remote Sensing of Environment, 79, 42-50. doi:10.1016/S0034-4257(01)00237-1.

Amankwah, E. (2013). Impact of illegal mining on water resources for domestic and irrigation purposes. ARPN Journal of Earth Sciences, 2, 117-121.

Aragon, F. M., \& Rud, J. P. (2013). Modern industries, pollution and agricultural productivity: Evidence from Ghana. International Growth Centre Working Paper, .

Armah, F. A., Obiri, S., Yawson, D. O., Onumah, E. E., Yengoh, G. T., Afrifa, E. K. A., \& Odoi, J. O. (2010). Anthropogenic sources and environmentally relevant concentrations of heavy metals in surface water of a mining district in 
Ghana: a multivariate statistical approach. Journal of environmental science and health. Part A, Toxic/hazardous substances $\mathcal{E}$ environmental engineering, 45, 1804-13. doi $10.1080 / 10934529.2010 .513296$.

Asner, G. P., Llactayo, W., Tupayachi, R., \& Luna, E. R. (2013). Elevated rates of gold mining in the Amazon revealed through high-resolution monitoring. Proceedings of the National Academy of Sciences of the United States of America, 110, 184549. URL: http://www.ncbi.nlm.nih.gov/pubmed/24167281http: //www.pubmedcentral.nih.gov/articlerender.fcgi?artid=PMC3832012. doi:10.1073/pnas.1318271110

Basommi, P. L., \& Guan, Q. (2015). Analysis of land use and land cover change in Nadowli District, Ghana. In 2015 23rd International Conference on Geoinformatics (pp. 1-6). IEEE. doi 10.1109/GEOINFORMATICS. 2015. 7378647.

Basommi, P. L., Guan, Q., \& Cheng, D. (2015). Exploring Land use and Land cover change in the mining areas of Wa East District, Ghana using Satellite Imagery. Open Geosciences, 7, 618-626. doi 10.1515/geo-2015-0058.

Boateng, D. O., Codjoe, F. N. Y., \& Ofori, J. (2014). Impact of illegal small scale mining (Galamsey) on cocoa production in Atiwa district of Ghana. International Journal of Advance Agricultural Research, (pp. 89-99).

Canty, M. J. (2015). Image Analysis, Classification and Change Detection in Remote Sensing: With Algorithms for ENVI/IDL and Python (Third Revised Edition). Taylor \& Francis CRC Press.

Canty, M. J., \& Nielsen, A. A. (2006). Visualization and unsupervised classification of changes in multispectral satellite imagery. International Journal of Remote Sensing, 27, 3961-3975. doi:10.1080/01431160500222608.

Canty, M. J., \& Nielsen, A. A. (2008). Automatic radiometric normalization of multitemporal satellite imagery with the iteratively re-weighted MAD transformation. Remote Sensing of Environment, 112, 1025-1036. doi:10.1016/j.rse.2007.07.013.

Crowley, G., \& Mackin, S. (2008). DMC data product manual. DMC International Imaging Ltd, .

Ecobank Group (2015). Mixed outlook for West Africas 2015/16 cocoa season. Technical Report EBI SA.

Fonseca, H. (2004). Mining, Social and Environmental Impacts. World Rainforest Movement, Montevideo, Uruguay, . doi 10.1.1.111.3899

Foody, G. M. (2002). Status of land cover classification accuracy assessment. Remote Sensing of Environment, 80, 185-201. URL: http: //www.sciencedirect.com/science/article/pii/S0034425701002954. doi: $10.1016 /$ S0034-4257(01)00295-4. 
Gallego, F. J. (2004). Remote sensing and land cover area estimation. International Journal of Remote Sensing, 25, 3019-3047. URL: http://www. informaworld.com/10.1080/01431160310001619607.

Hilson, G. (2002). The environmental impact of small-scale gold mining in Ghana: identifying problems and possible solutions. Geographical Journal, $168,57-72$.

Hilson, G., \& Garforth, C. (2013). Everyone Now is Concentrating on the Mining: Drivers and Implications of Rural Economic Transition in the Eastern Region of Ghana. Journal of Development Studies, 49, 348-364. doi10.1080/ 00220388.2012 .713469 .

ISSER (2015). Overview: Global Economic Developments and Ghanas Economic Performance. In The State of the Ghanaian Economy in 2014 chapter 1. University of Ghana: Institute of Statistical, Social, Economic.

Kusimi, J. M. (2008). Assessing land use and land cover change in the Wassa West District of Ghana using remote sensing. GeoJournal, 71, 249-259. doi:10.1007/s10708-008-9172-6.

Kusimi, J. M., Amisigo, B. A., \& Banoeng-Yakubo, B. K. (2014). Sediment yield of a forest river basin in Ghana. CATENA, 123, 225-235. doi 10.1016/ j.catena.2014.08.001.

Lobo, F. L., Costa, M. P. F., \& Novo, E. M. L. M. (2015). Time-series analysis of Landsat-MSS/TM/OLI images over Amazonian waters impacted by gold mining activities. Remote Sensing of Environment, 157, 170-184. doi-10. 1016/j.rse.2014.04.030

Makarau, A., Richter, R., Muller, R., \& Reinartz, P. (2014). Haze detection and removal in remotely sensed multispectral imagery. IEEE Transactions on Geoscience and Remote Sensing, 52, 5895-5905. doi:10.1109/TGRS.2013. 2293662 .

Manu, A., Twumasi, Y. A., \& Coleman, T. L. (2004). Application of remote sensing and GIS technologies to assess the impact of surface mining at Tarkwa, Ghana. In IEEE International IEEE International IEEE International Geoscience and Remote Sensing Symposium, 2004. IGARSS '04. Proceedings. 2004 (pp. 572-574). IEEE volume 1. doi:10.1109/IGARSS.2004.1369091.

Milisavljevic, N., Closson, D., \& Bloch, I. (2010). Detecting potential human activities using coherent change detection. In 2010 2nd International Conference on Image Processing Theory, Tools and Applications (pp. 482485). IEEE. URL: http://ieeexplore.ieee.org/document/5586772/ doi:10.1109/IPTA.2010.5586772.

Nielsen, A. A., Conradsen, K., \& Simpson, J. J. (1998). Multivariate alteration detection (MAD) and MAF postprocessing in multispectral, bitemporal image data: New approaches to change detection studies. Remote Sensing of Environment, 64, 1-19. doi 10.1016/S0034-4257(97)00162-4. 
Okoh, G., \& Hilson, G. (2011). Poverty and livelihood diversification: Exploring the linkages between smallholder farming and artisanal mining in rural ghana. Journal of International Development, 23, 1100-1114. doi10.1002/ jid.1834

Opare, J. K. L., Ohuabunwo, C., Afari, E., Wurapa, F., Sackey, S. O., Der, J., Afakye, K., \& Odei, E. (2012). Outbreak of cholera in the East Akim Municipality of Ghana following unhygienic practices by small-scale gold miners, November 2010. Ghana medical journal, 46, 116-23.

Platnick, S., King, M. D., Ackerman, S. A., Menzel, W. P., Baum, B. A., Riedi, J. C., \& Frey, R. A. (2003). The MODIS cloud products: algorithms and examples from terra. IEEE Transactions on Geoscience and Remote Sensing, 41, 459-473. URL: http://ieeexplore.ieee.org/lpdocs/ epic03/wrapper.htm?arnumber=1196061. doi $10.1109 /$ TGRS .2002.808301

Plourde, L., \& Congalton, R. (2003). Sampling method and sample placement: How do they affect the accuracy of remotely sensed maps? Photogrammetric Engineering and Remote Sensing, 69, 289-297.

Serfor-Armah, Y., Nyarko, B. J. B., Adotey, D. K., Adomako, D., \& Akaho, E. H. K. (2004). The impact of small-scale mining activities on the levels of mercury in the environment: The case of Prestea and its environs. Journal of Radioanalytical and Nuclear Chemistry, 262, 685-690. doi:10.1007/s10967-004-0493-8.

Teschner, B. A. (2012). Small-scale mining in Ghana: The government and the galamsey. Resources Policy, 37, 308-314. doi 10.1016/j.resourpol.2012. 02.001 . 